\title{
Cadastral and Tea Production Management System with Wireless Sensor Network, GIS based System and IoT Technology
}

\author{
Kohei Arai \\ Information Science Department \\ Graduate School of Science and Engineering, Saga University \\ Saga City, Japan
}

\begin{abstract}
Cadastral and tea production management system utilizing wireless sensor network of Internet of Things (IoT) technology is proposed. To improve efficiency of tea productions, cadastral management and tea production processes must be managed by Geographical Information System (GIS) based system. Through experiments with sensor acquired data, it is found that the required information can be estimated and represented efficiently. Thus, the system works for improvement of the tea production management and quality control.
\end{abstract}

Keywords-Internet of Things; geographical information system; tea production; quality control

\section{INTRODUCTION}

Vegetation monitoring is attempted with red and photographic cameras [1]. Growth rate monitoring is also attempted with spectral observation [2].

Total nitrogen content corresponds to amid acid which is highly correlated to Theanine: 2-Amino-4-(ethyl carbamoyl) butyric acid for tealeaves so that total nitrogen is highly correlated to tea taste. Meanwhile fiber content in tealeaves has a negative correlation to tea taste. Near Infrared: NIR camera data shows a good correlation to total nitrogen and fiber contents in tealeaves so that tealeaves quality can be monitored with network NIR cameras. It is also possible to estimate total nitrogen and fiber contents in leaves with remote sensing satellite data, in particular, Visible and Near Infrared: VNIR radiometer data. Moreover, Vegetation Cover: VC, Normalized Difference Vegetation Index: NDVI, Bi-Directional Reflectance Distribution Function: BRDF of tealeaves have a good correlation to growth index of tealeaves so that it is possible to monitor expected harvest amount and quality of tealeaves with network cameras together with remote sensing satellite data. BRDF monitoring is well known as a method for vegetation growth [3], [4]. On the other hand, degree of polarization of vegetation is attempted to use for vegetation monitoring [5], in particular, Leaf Area Index: LAI together with new tealeaves growth monitoring with BRDF measurements [6].

It is obvious that nitrogen rich tealeaves tastes good while fiber rich tealeaves tastes bad. Theanine: 2-Amino-4-(ethyl carbamoyl) butyric acid that is highly correlated to nitrogen contents in new tealeaves are changed to catechin [7],[8],[9] due to sun light. In accordance with sunlight, new tealeaves growth up so that there is a most appropriate time for harvest in order to maximize amount and taste of new tealeaves simultaneously.

Optical properties of tealeaves and methods for estimation of tealeaves quality and harvest amount estimation accuracy are well reported [10]-[17]. The method proposed here is to determine tealeaves harvest timing by using NIR camera images together with meteorological data. Also, the methods for estimation of vitality of tea trees (vigor) and tealeaf quality assessment are proposed together with Kyushu small satellite based tea farm area monitoring [18]-[23]. Multi-layer observation for agricultural (tea and rice) field monitoring system is proposed by the author [24], [25].

In this paper, cadastral and tea production management system utilizing wireless sensor network of Internet of Things: IoT technology is proposed. In order to improve efficiency of tea productions, cadastral management and tea production processes have to be managed by Geographical Information System: GIS based system. Through experiments at the Saga Prefectural Tea Institute situated in Kyushu, Japan with sensor acquired data, it is found that the required information can be estimated and represented efficiently. Also, it is found that the system works for improvement of the tea production management and quality control. The growth rate indicates fiber content in tealeaves while total nitrogen content in tealeaves is highly correlated with taste of tea. The vegetation monitoring should have both capabilities, fiber and nitrogen contents in tealeaves. Thus the proposed system allows to monitor the age and the taste of tealeaves with GIS system after observation.

The following section describes the proposed cadastral management system based on GIS representation. Then the proposed tea production control system with wireless sensor network is described together with some experiments conducted with the proposed system. Finally, conclusion is described with some discussions.

\section{Proposed TeA Production MANAGEMENT System}

\section{A. System Configuration}

Fig. 1 shows a portion of the proposed tea production management system. In the tea farm areas situated in Ureshinocity, Kyushu, Japan, ground based visible to near infrared 
cameras are equipped for monitoring of tealeaf growing processes (fiber content in tealeaf) and tealeaf quality (Nitrogen content in tealeaf). Visible Pan-Tilt-Zoom: PTZ network camera and NIR filter (IR840) attached network camera is equipped on the pole. PTZ cameras are controlled by mobile phone as well with "mobile2PC" or Internet terminal with "LogMeIn" of VNC services [7] through wireless LAN connected to Internet. Acquired camera data are used for estimation of total nitrogen and fiber contents as well as BRDF for monitoring growth index.

The cameras are connected to the Internet through the network card of W05K that is provided by AU/KDDI. Through http://119.107.81.166:8080, the acquired image data are accessible so that it is easy to access the data from Internet terminals. Panasonic BB-HCM371 cameras are used for the experiments. Solar panel of G-500 (12V, 500mA, 8.5W) with battery of SG-1000 is used together with Xpower75 (60W) of inverter. On the other hand, weather station data can be accessible from the URL of http://katy.jp/mapstation/ of data server provider through wireless LAN connection from the weather station to the Internet terminal. Acquired imagery data can be transferred to the central station together with meteorological data. Therefore, tealeaf growing process and tea quality can be monitored in the central station. Also, the acquired images and information can be monitored with mobile terminals.

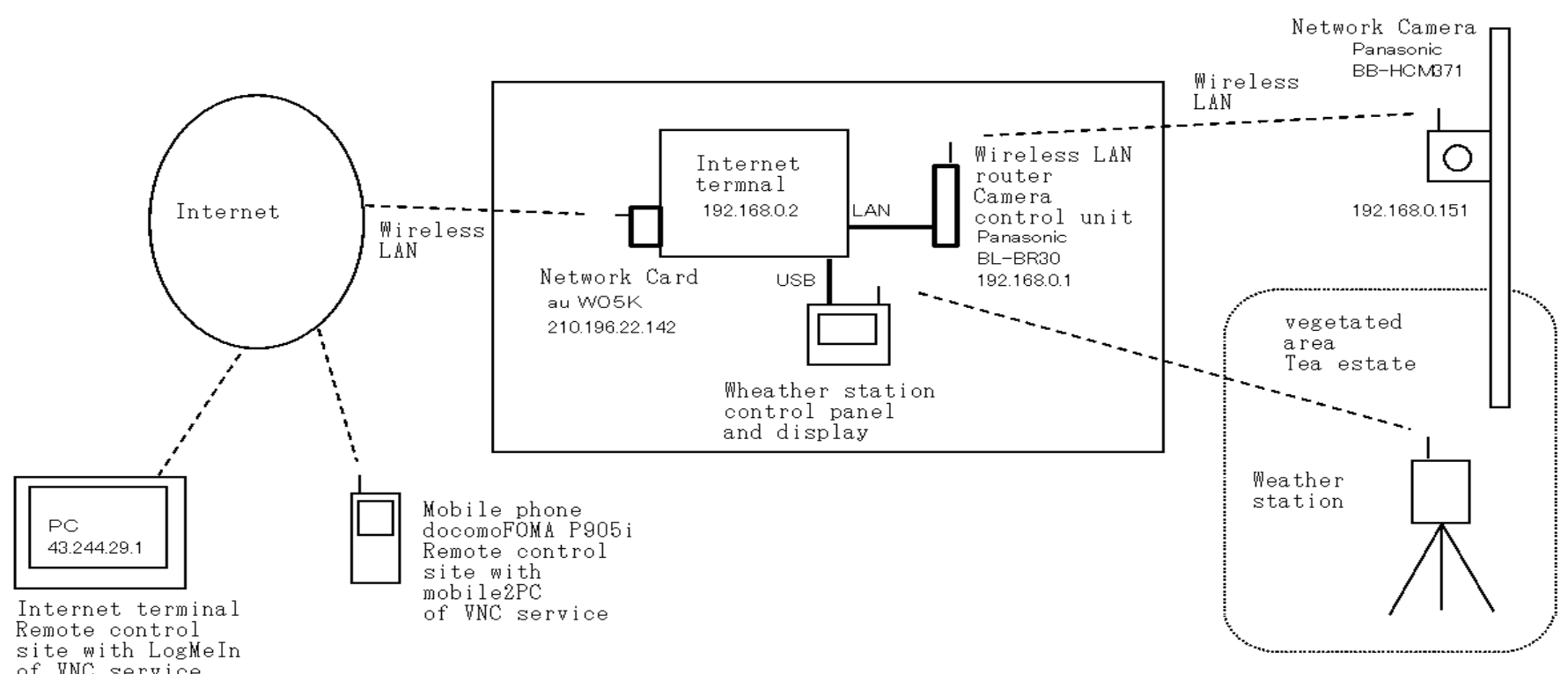

Fig. 1. Proposed wireless sensor network system configuration.

\section{B. Cadastral Management and GIS Representation of all the Required Data and Information for Tealeaf Growthing and Quality Monitoring of Tea Farm Areas}

Cadastral management can be performed with the following procedure: First, entire topographic map of the Saga prefecture is represented with the map scale of $1 / 100,000$ in GIS as shown in Fig. 2(a). In the proposed system, SuperMap DeskPro of GIS ${ }^{1}$ system is used. The GIS system has the following functions, Data Editing, Thematic Map, Topology, Attribute creation, Layout, Spatial analysis, Grid analysis, Network analysis. 3D analysis. Red circles in Fig. 2(a) indicate the tea farm areas as points. Then the tea farm areas are represented with the map scale of $1 / 25,000$ as shown in Fig. 2(b). In this stage, polygons are used for tea farm areas. Thus area of the specific tea farm can be calculated.

Also, all kinds of parameters are displayed in the GIS map such as owner's name, latitude, longitude, elevation, tea tree species, ID No., observation date and time, etc. Smart snapshot, topology process, registration process, control point location input, attribute table relation, hyperlink function,

\footnotetext{
${ }^{1}$ https://supermap.jp/products/supermap/deskpro/d_viewer.html
}

spatial analysis including area calculation, buffering, overlaying analysis and geometric calculation are also available in this stage. Much large scale of map can be available up to $1 / 15,000$ at this stage as shown in Fig. 2(c). Through these process, 1/1,500 map scale representation is available as shown in Fig. 2(d).

The corresponding areas of satellite imagery data to the topographic map areas can also be displayed in the GIS map as shown in Fig. 2(e). In this case, pan-sharpened image between Advanced Land Observation Satellite: ALOS/PRISM (Panchromatic band of visible sensor) and Terra (the first Earth Observing Satellite System: EOS satellite) /Advanced Sensor for Thermal Emission and Reflectance: ASTER/Visible and Near Infrared Radiometer: VNIR is displayed (2 $\mathrm{m}$ of spatial resolution of multispectral imagery data can be created by the pan-sharpened process ${ }^{2}$. These data are linked to not only satellite imagery data but also the ground based NIR camera data. Therefore, the corresponding linked camera data to the clicked GIS map location is displayed as shown in Fig. 2(f).

\footnotetext{
${ }^{2}$ RGB coordinate system of VNIR is converted to HIS system. Then Intensity is replaced by PRISM data. After that, HIS system is converted to RGB system.
} 


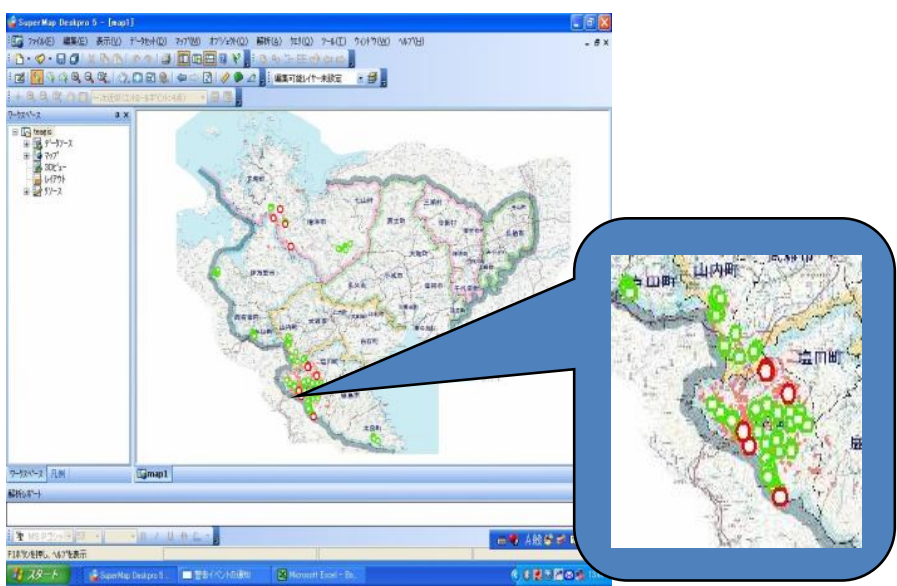

(a) Entire Saga prefecture.

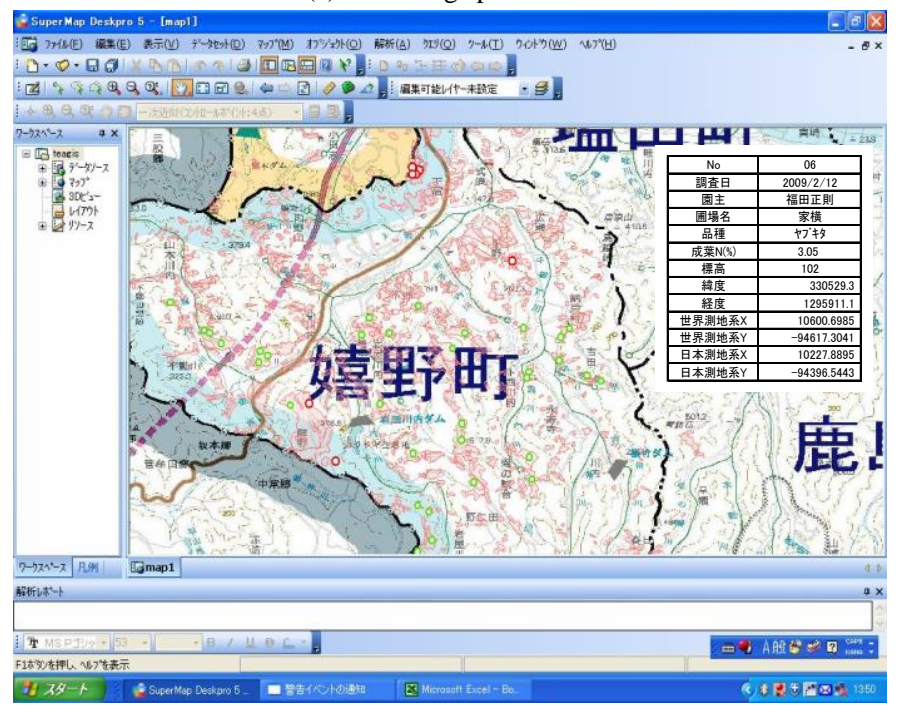

(b) Close-up for each tea farm area.

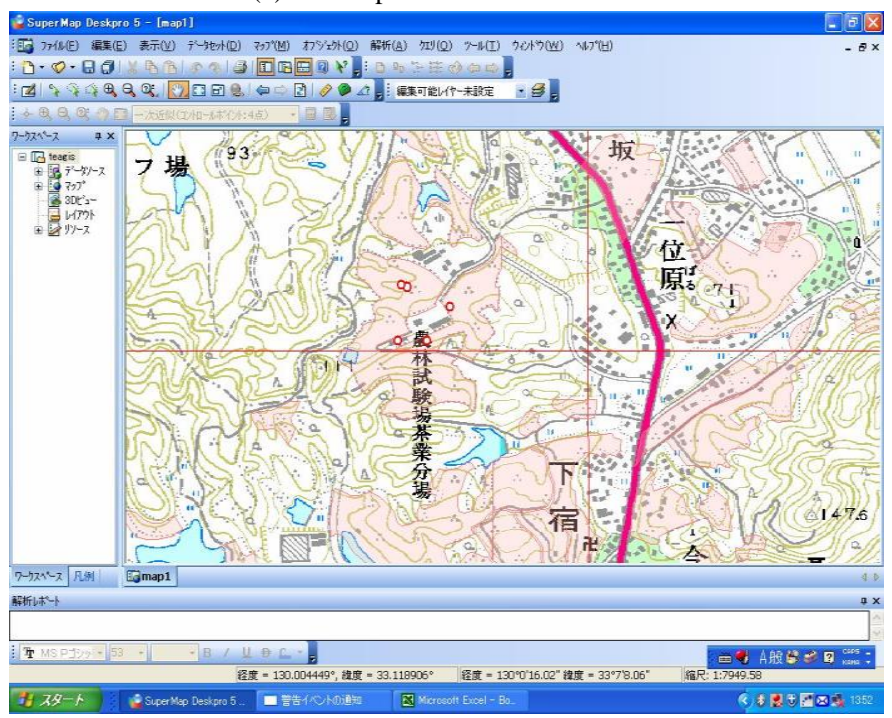

(c) $1 / 15,000$ scale map representation.

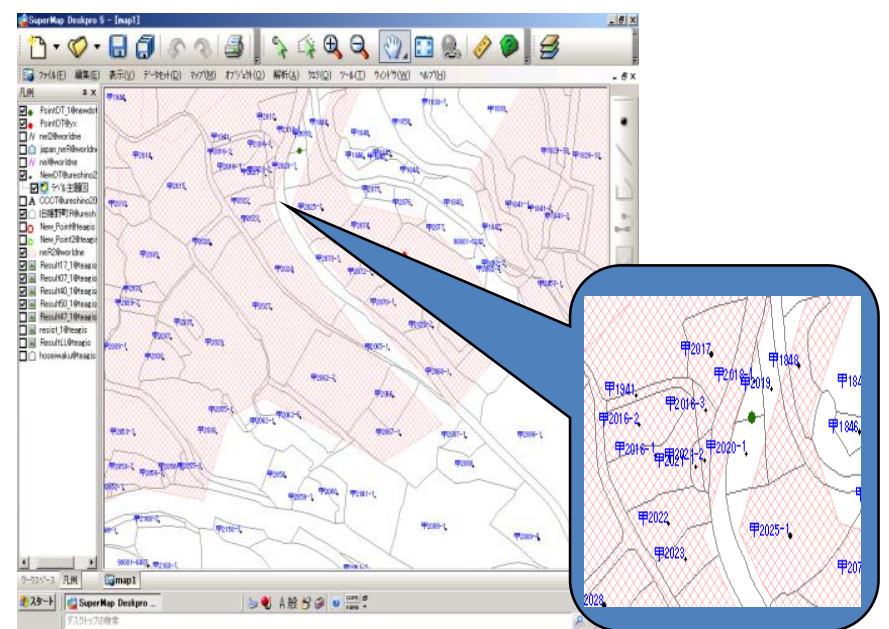

(d) $1 / 1,500$ scale map representation.

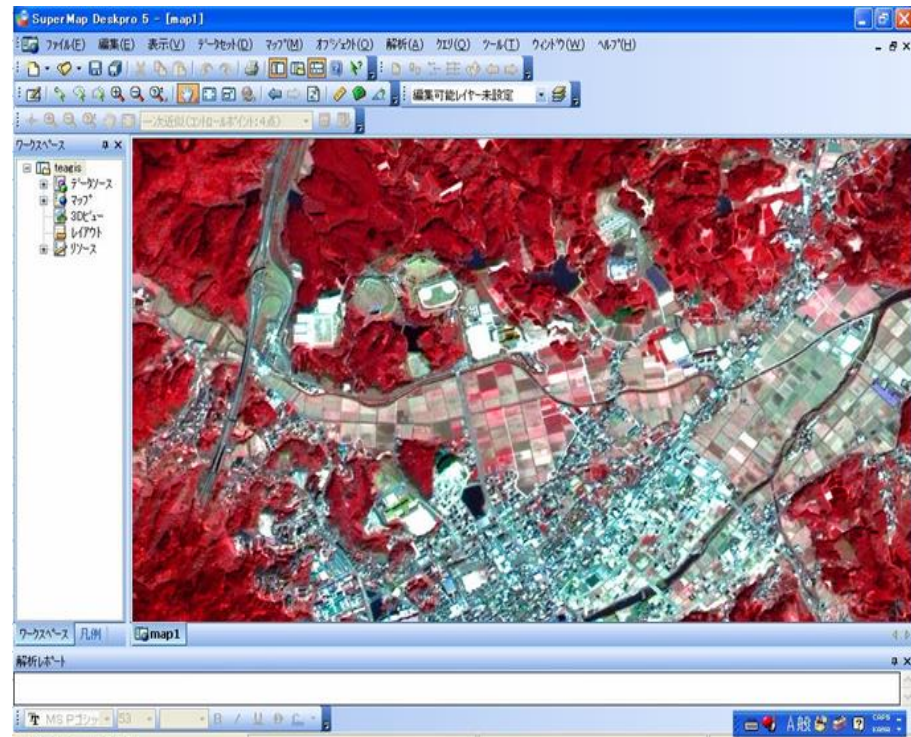

(e) Pan-sharpened image between ALOS/AVNIR-2 and Terra/ASTER/VNI.

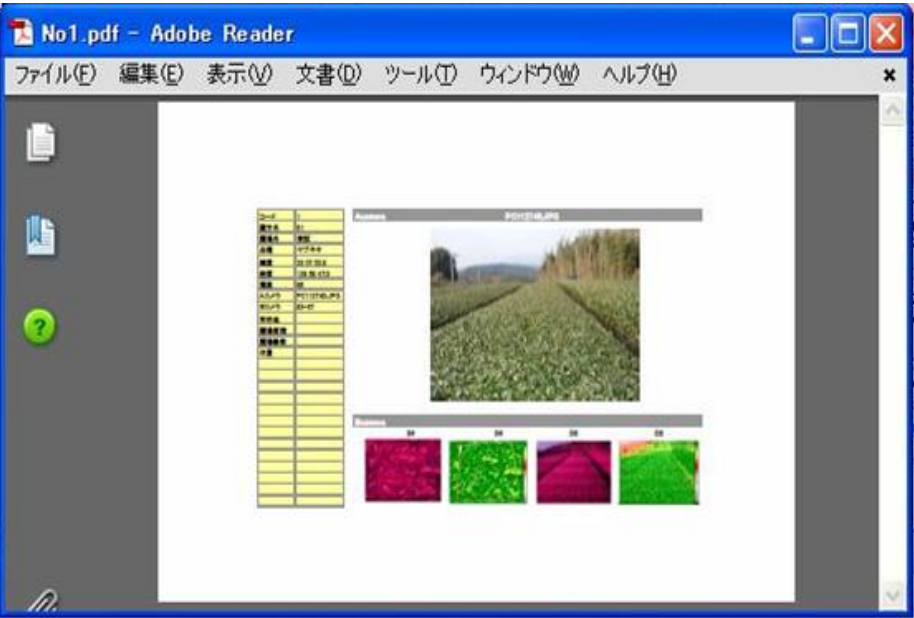

(f) Linked camera imagery data. 


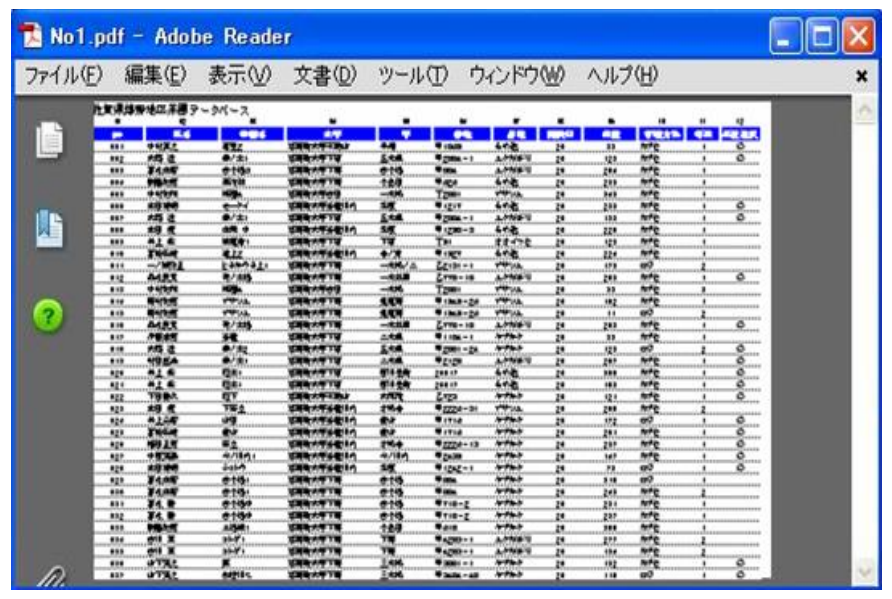

(g) All the required data and information.

Fig. 2. Cadastral Management and GIS representation of all the required data and information for tealeaf growing and quality monitoring of tea farm areas.

Thus all the required data and information for tealeaf production (tealeaf growing and quality) are displayed by clicking the location of tea farm areas on the GIS map as shown in Fig. 2(g). As shown in Fig. 2(g), the proposed GIS system allows monitoring of each tea farm field. Therefore, fertilizer, water resources, pesticide can be controlled by the data shown by GIS system by field by field. Furthermore, it can be done to arrange almost same quality of harvested tealeaves for tea production by taking a look at the quality of tealeaves in concern with the GIS system. The aforementioned function, data handling and analysis can be done in the GIS system as well.

\section{EXPERIMENTS WITH THE PROPOSED SYSTEM}

\section{A. Optical Property of Tealeaf}

The most specific optical property of tealeaf is spectral reflectance. Fig. 3 shows examples of typical spectral reflectance.

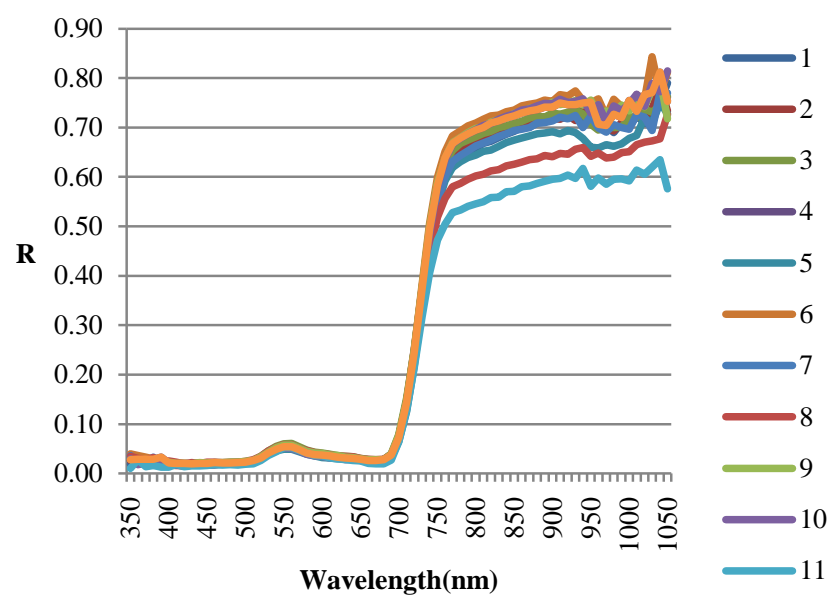

Fig. 3. Examples of spectral reflectance of tealeaves.
In the figure, spectral reflectance of 10 different tea farm areas situated in Ureshino-city, Saga, Japan are shown in Fig.3. The most specific feature of the spectral reflectance is high reflectance in the near-infrared spectral region followed by relatively high reflectance at the $550 \mathrm{~nm}$, green color of spectral range. Chloroplast under the cuticle of tealeaf shows high reflectance at the near-infrared wavelength region $(935 \mathrm{~nm})$ depending on the interval between cells. The difference among the reflectance at near-infrared wavelength region indicates their quality, in particular, total nitrogen content in the tealeaves which corresponds to amino acid (Theanine) content. Therefore, tealeaf quality can be estimated with the measured reflectance at near-infrared wavelength region. The measured spectral reflectance at near-infrared region is transmitted to the cadastral and tea production management center with wireless sensor network through internet. Therefore, quality of the different tea farm areas can be monitored and estimated. Using high quality of tealeaves, high quality of bland tea (High quality tea qualified by satellites) can be produced.

\section{B. Other Property of Tealeaf}

Traditionally, GM(Green Meter) value is an indicator of the quality of tealeaf. GM can be measured with the commercially available GM meter (a kind of touch sensor) with relatively low cost. Therefore, most of tea farmers use the GM meter. Essentially, GM indicate the reflectance of tealeaf at the green wavelength. As shown in Fig. 3, there is strong relation between reflectance at near-infrared and green wavelength regions. As the result, it is possible to estimate GM value by using the measure reflectance at the near-infrared. Also, Total Nitrogen (TN) content in tealeaf is highly related to the reflectance at the near-infrared wavelength region. Fig. 4(a) and (b) shows residual errors of GM and TM predictions, respectively. Also, Fig. 4(c) and (d) shows the relation between estimated and actual TN as well as the regressive analysis result of water content in the tealeaves with the reflectance at near-infrared wavelength region, respectively. All these regressive analysis show a good correlation in terms of residual errors for GM and TN as well as estimations of water content and $\mathrm{TN}$ in tealeaves.

Therefore, it may be said that GM, TN and water content in tealeaf can be estimated with the measured reflectance at the near-infrared wavelength region.

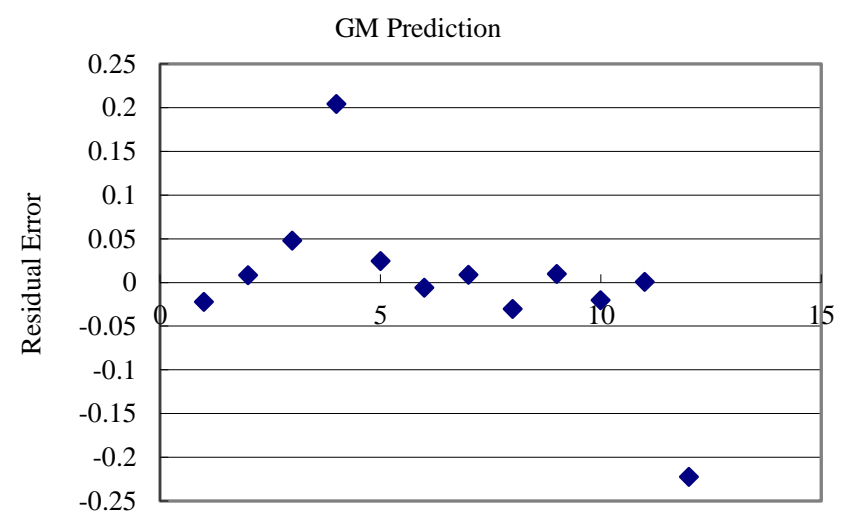

(a) GM. 


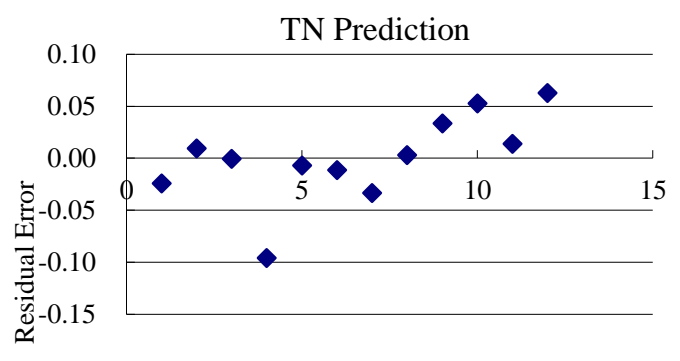

(b) TN.

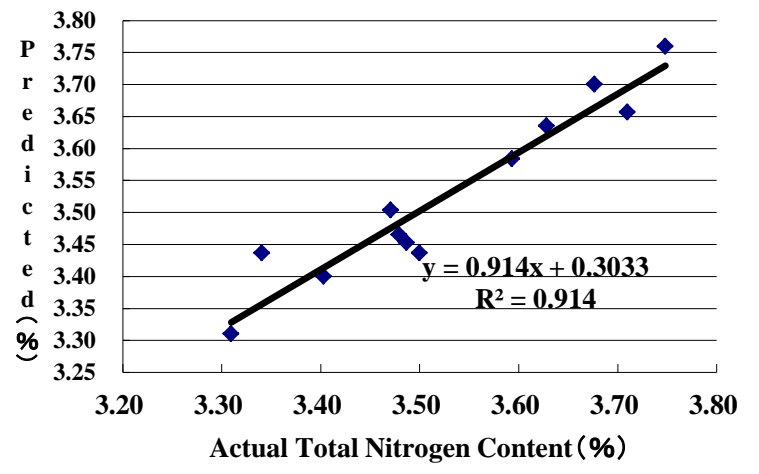

(c) Relation between estimated and actual TN.

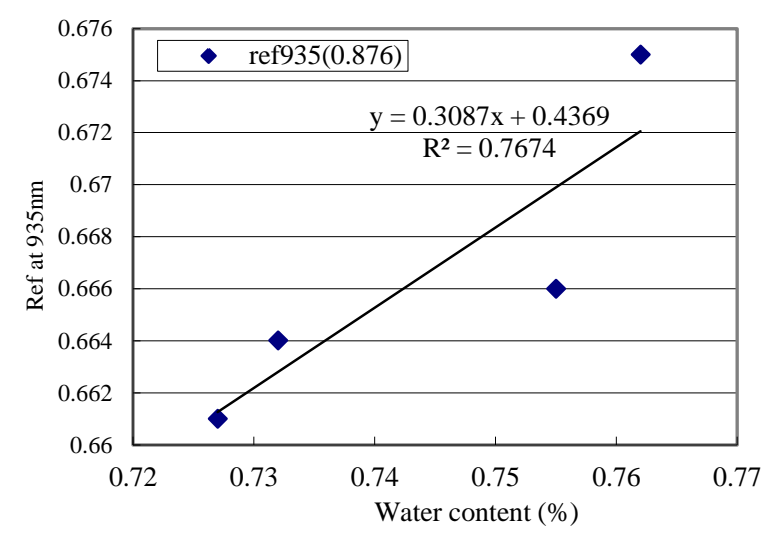

(d) Water content.

Fig. 4. Regressive analysis results of GM and TN predictions using the measured reflectance at near-infrared wavelength region.

Another important factor of tealeaf quality is fiber content (F-NIR). Fiber rich tealeaf implies elder tealeaf while fiber poor tealeaf means young tealeaf. Obviously, younger tealeaf is better than that of elder tealeaf. Fiber content in tealeaf can be estimated with reflectance at near-infrared wavelength region.

Fig. 5 shows the relation between reflectance at $935 \mathrm{~nm}$ and $\mathrm{TN}$ as well as fiber content in tealeaves. The $\mathrm{R}$ square value (square of correlation between both) is not good enough, around 0.74 . Therefore, another index which shows much high correlation has to be found. Normalized Difference Vegetation Index: NDVI is well-known index for vegetation. If the spectral reflectance is measured with spectrometers, then reflectance at arbitrary wavelength can be used for estimation of TN and fiber content. The best index for estimation of TN and fiber content is determined through regressive analysis with the measured spectral reflectance.

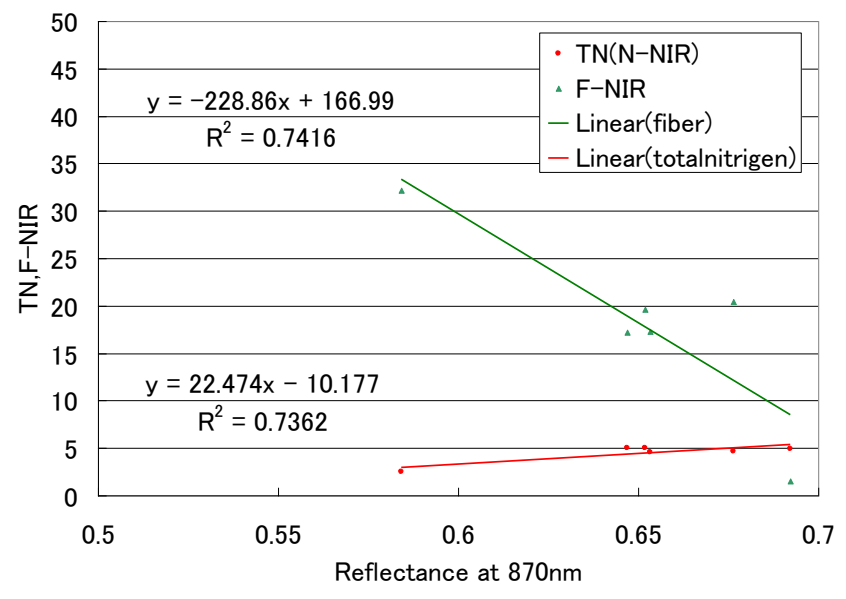

Fig. 5. Relation between the reflectance at $870 \mathrm{~nm}$ and $\mathrm{TN}$ as well as fiber content in tealeaves.

Fig. 6 shows the regressive analysis results for TN and fiber content estimations. The results show that the TN and fiber content estimations with Arai's index is better than those estimations with the conventional wavelength of reflectance and NDVI.

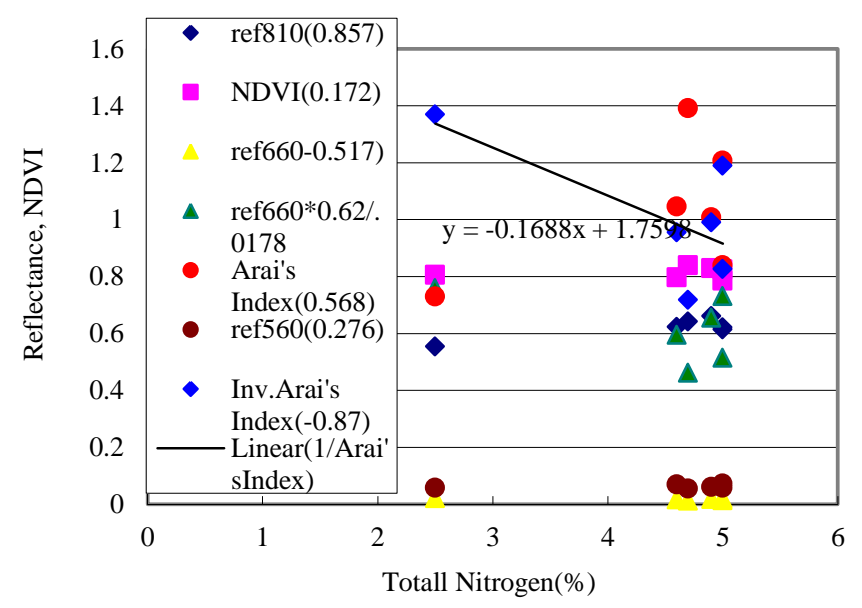

(a) $\mathrm{TN}$.

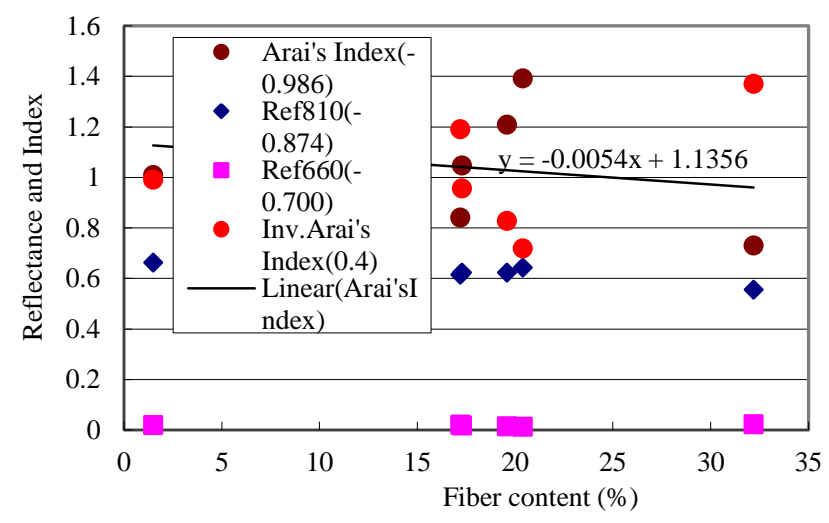

(b) Fiber content.

Fig. 6. Best index for estimation of $\mathrm{TN}$ and fiber content in tealeaf. 


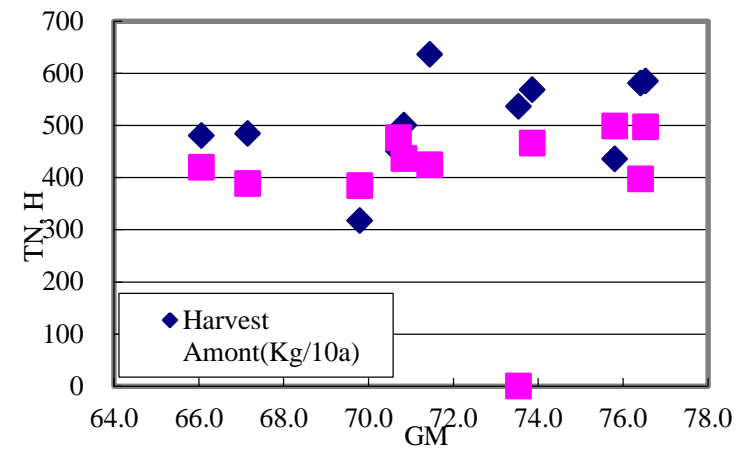

Fig. 7. Relation between GM value and TN as well as harvest amount in unit of $\mathrm{Kg} / 10 \mathrm{a}$.

\section{Harvest Amount Estimation}

Other important factor for tea farm area evaluation is harvest amount which is highly correlated to GM value. Fig. 7 shows the relation between $\mathrm{GM}$ value and $\mathrm{TN}$ as well as harvest amount in unit of $\mathrm{Kg} / 10 \mathrm{a}$. As shown in Fig. 4, GM value is highly correlated to the reflectance at near-infrared wavelength region. Therefore, harvest amount can be estimated with the measured reflectance at near-infrared wavelength region.

The harvest amount of tealeaf is also highly correlated to the tea tree age. In general, expected tea quality and harvest amount proportional to their age as shown in Fig. 8. Also, vitality of tea trees are getting down with tea tree age of around 50 .

\section{Trend Analysis of Total Nitrogen Content in Tealeaf}

$\mathrm{TN}$ is changing for time being. During from October to March next year, tea tree keeps their vigor, or vitality. From the begging of April to the begging of May, tea tree has new tealeaves. Then the new tealeaves are harvested in the middle of May. After that, new tealeaves are born again from the middle of May to July. Then the second new tealeaves are harvested in July. From August to September, new tealeaves are born and growth up followed by third harvesting in October. This is the typical annual cycle of tea trees. Tealeaf quality and harvest amount is varied due to weather conditions, fertilizer, water supply, insect damage, and so on. That is why the total nitrogen content in tealeaves is changeable as shown in Fig. 9.

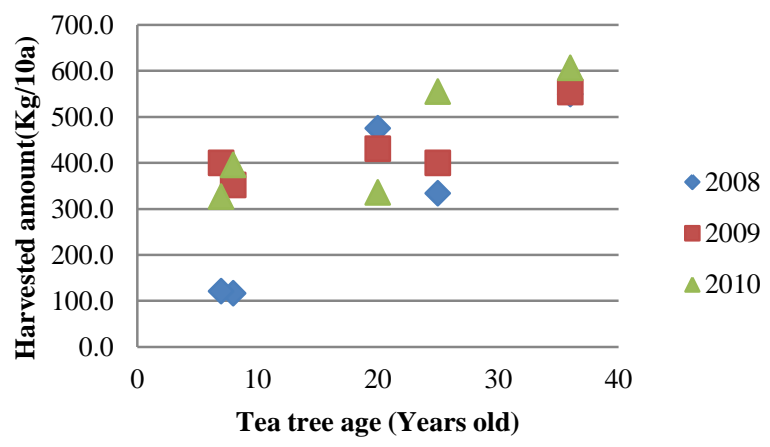

Fig. 8. Expected tea quality and harvest amount proportional to their age.

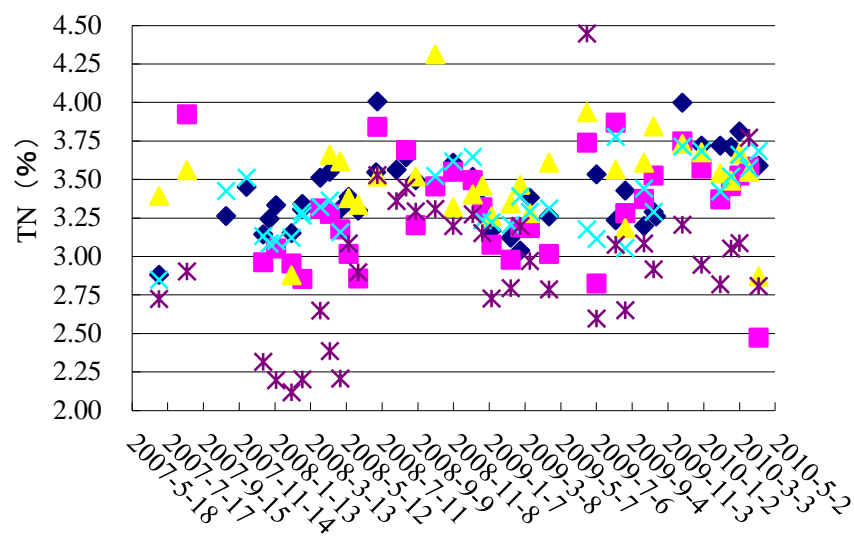

Fig. 9. Seasonal and annual changes of TN of tea farm areas situated at the 10 different farm areas in Ureshino, Saga, Japan during from 2007 to 2010.

Such the trend analysis can be done with the proposed Cadastral and Tea Production Management System with Wireless Sensor Network.

\section{CONCLUSION}

Cadastral and tea production management system utilizing wireless sensor network of Internet of Things (IoT) technology is proposed. In order to improve efficiency of tea productions, cadastral management and tea production processes have to be managed by Geographical Information System: GIS based system. Through experiments with sensor acquired data, it is found that the required information (quality: Total Nitrogen, Fiber Content, Water Content in tealeaves and harvest amount) can be estimated and represented efficiently. Thus the system works for improvement of the tea production management and quality control. For instance, it is possible to reduce tea farmer's labor cost about half (the number of look around monitoring). Fertilizer, pesticide and water resources can be reduced approximately $20 \%$.

Further investigation is required for remote sensing satellite big data analysis utilizing Artificial Intelligence. Time series analysis for estimation of tealeaf quality and harvest amount can be done with AI much accurately.

\section{ACKNOWLEDGMENT}

Author would like to thank Dr. Hideo Miyazaki of the Saga Prefectural Tea Research Institute for his cooperation through this research work.

\section{REFERENCES}

[1] J.T.Compton, Red and photographic infrared linear combinations for monitoring vegetation, Journal of Remote Sensing of Environment, 8, 127-150, 1979.

[2] C.Wiegand, M.Shibayama, and Y.Yamagata, Spectral observation for estimating the growthth and yield of rice, Journal of Crop Science, 58, 4, 673-683, 1989.

[3] S.Tsuchida, I.Sato, and S.Okada, BRDF measurement system for spatially unstable land surface-The measurement using spectroradiometer and digital camera- Journal of Remote Sensing, 19, 4, 49-59, 1999.

[4] K.Arai, Lecture Note on Remote Sensing, Morikita-shuppan Co., Ltd., 2000.

[5] K.Arai and Y.Nishimura, Degree of polarization model for leaves and discrimination between pea and rice types of leaves for estimation of leaf area index, Abstract, COSPAR 2008, A3.10010-08\#991, 2008. 
[6] K.Arai and Long Lili, BRDF model for new tealeaves and new tealeaves monitoring through BRDF monitoring with web cameras, Abstract, COSPAR 2008, A3.10008-08\#992, 2008.

[7] Greivenkamp, John E., Field Guide to Geometrical Optics. SPIE Field Guides vol. FG01. SPIE. ISBN 0-8194-5294-7, 2004.

[8] Seto R H. Nakamura, F. Nanjo, Y. Hara, Bioscience, Biotechnology, and Biochemistry, Vol.61 issue9 1434-1439 1997.

[9] Sano M, Suzuki M ,Miyase T, Yoshino K, Maeda-Yamamoto, M.,J.Agric.Food Chem., 47 (5), 1906-1910 1999.

[10] Kohei Arai, Method for estimation of growth index of tealeaves based on Bi-Directional reflectance function: BRDF measurements with ground based network cameras, International Journal of Applied Science, 2, 2, 52-62, 2011.

[11] )Kohei Arai, Wireless sensor network for tea estate monitoring in complementally usage with Earth observation satellite imagery data based on Geographic Information System(GIS), International Journal of Ubiquitous Computing, 1, 2, 12-21, 2011.

[12] Kohei Arai, Method for estimation of total nitrogen and fiber contents in tealeaves with ground based network cameras, International Journal of Applied Science, 2, 2, 21-30, 2011.

[13] Kohei Arai, Monte Carlo ray tracing simulation for bi-directional reflectance distribution function and growth index of tealeaves estimation, International Journal of Research and Reviews on Computer Science, 2, 6, 1313-1318, 2011.

[14] K.Arai, Monte Carlo ray tracing simulation for bi-directional reflectance distribution function and growth index of tealeaves estimations, International Journal of Research and Review on Computer Science, 2, 6, 1313-1318, 2012

[15] K.Arai, Fractal model based tea tree and tealeaves model for estimation of well opened tealeaf ratio which is useful to determine tealeaf harvesting timing, International Journal of Research and Review on Computer Science, 3, 3, 1628-1632, 2012.

[16] Kohei Arai, Method for tealeaves quality estimation through measurements of degree of polarization, leaf area index, photosynthesis available radiance and normalized difference vegetation index for characterization of tealeaves, International Journal of Advanced Research in Artificial Intelligence, 2, 11, 17-24, 2013.

[17] K.Arai, Optimum band and band combination for retrieving total nitrogen, water, and fiber in tealeaves through remote sensing based on regressive analysis, International Journal of Advanced Research in Artificial Intelligence, 3, 3, 20-24, 2014.

[18] Kohei Arai, Hideo Miyazaki, Masayuki Akaishi, Tea tree vitality evaluation method and appropriate harvesting timing determination method based on visible and near infrared camera data, Journal of Japan Society of Photogrammetry and Remote Sensing, 51, 1, 38-45, 2012.

[19] K.Arai, Optimum band and band combination for retrieving total nitrogen, water, and fiber in tealeaves through remote sensing based on regressive analysis, International Journal of Advanced Research in Artificial Intelligence, 3, 3, 20-24, 2014.

[20] Kohei Arai, Kyushu small satellite for remote sensing (QSAT/EOS) and value added tealeaves "Eisei-no-megumi Ureshino-cha", Journal of Society for Instrument Control Engineering of Japan, 53, 11, 988-996, 2014

[21] Kohei Arai, Yoshihiko Sasaki, Shihomi Kasuya, Hideto Matsuura, Appropriate teleaf harvest timing determination based on NIR images of tealeaves, Internationa Journal of Information Technology and Computer Science, 7, 7, 1-7, 2015

[22] Kohei Arai, Yoshihiko Sasaki, Shihomi Kasuya, Hideo Matsura, Appropriate harvest timing determination reffering fiber content in tealeaves derived from ground based NIR camera images, International Journal of Advanced Research on Artificial Intelligence, 4, 8, 26-33, 2015.

[23] K.Arai, Method for Vigor Diagonosis of Tea Trees Based on Nitorgen Content in Tealeaves Relating to NDVI, International Journal of Advanced Research on Artificial Intelligence, 5, 10, 24-30, 2016.

[24] Kohei Arai, Bigdata Platform for agricultural field monitoring and environmental monitoring, Proceedings of the 4th LISAT Symposium (Invited Speech), p.37, 2017.

[25] Kohei Arai, Multi-Layer Observation for Agricultural (Tea and Rice) Field Monitoring, Proceedings of the Seminor at Bogor Agriculture University, Keynote Speech, 2016.

\section{AUTHORS PROFILE}

Kohei Arai. He received BS, MS and PhD degrees in 1972, 1974 and 1982, respectively. He was with The Institute for Industrial Science and Technology of the University of Tokyo from April 1974 to December 1978 and also was with National Space Development Agency of Japan from January, 1979 to March, 1990. During from 1985 to 1987, he was with Canada Centre for Remote Sensing as a Post-Doctoral Fellow of National Science and Engineering Research Council of Canada. He moved to Saga University as a Professor in Department of Information Science on April 1990. He was a counselor for the Aeronautics and Space related to the Technology Committee of the Ministry of Science and Technology during from 1998 to 2000 . He was a councilor of Saga University for 2002 and 2003. He also was an executive councilor for the Remote Sensing Society of Japan for 2003 to 2005 . He is an Adjunct Professor of University of Arizona, USA since 1998. He also is Vice Chairman of the Commission-A of ICSU/COSPAR since 2008. He received Science and Engineering Award of the year 2014 from the minister of the ministry of Science Education of Japan and also received the Best Paper Award of the year 2012 of IJACSA from Science and Information Organization: SAI. In 2016, he also received Vikram Sarabhai Medal of ICSU/COSPAR and also received 37 awards. He wrote 37 books and published 570 journal papers as well as 370 conference papers. He is Editor-in-Chief of International Journal of Advanced Computer Science and Applications as well as International Journal of Intelligent Systems and Applications. http://teagis.ip.is.saga-u.ac.jp/ 